\title{
Thoughts on The Twinning of Communication and Media
}

\author{
By Linda Bartrom
}

$\mathbf{F}$ or most disciplines, the goal of the educational program, the output as it were, and the materials through which it is developed, are entirely different species. For example, the sciences have conceptual goals as well as quantitative, in which the fundamental facts and theses are taught and then interrelated by means of formulas. These facts and the mathematics which interrelates them are transmitted through various pedagogical tools, inclusive of textbooks, calculation exercises, physical demonstrations, laboratory use of the scientific method for data gathering, and emergent skill with the equipment used in that discipline.

In media, however, the goal: communication, and the materials used to transmit it: the media, are incredibly interwoven and in many instances the same. To learn to use the camera a student learns to use a camera. To learn to run a sound board, the learner uses a sound board. To learn to speak on camera, the cast speak on camera. For those learning their craft in the communications field, the goal and the methodology are the very much the same and virtually always co-present during learning and execution. This may appear to make the media course simpler but in truth it makes it more difficult, for the crucial role of mastering the tools of the trade is the complete predictor of the success of the lesson. Both the goal of the program, and the facts and materials used to transmit it, are nearly identical. This creates an interesting paradox, which is further complicated by the nature of production: the presence of an audience. This audience who receives the information has a right to truth and fact, returning us to the topic of media's twin: communication.

Communication is the process of transferring information from one entity to another, i.e. sharing, and media are the tools used to store and deliver that information. The interwoven nature of these two, their interdependence as it were, does not negate the need for them to be clearly separated for students, it increases that need. Often, the emphasis on media overrides the topic of comminication. For example, a previous column dealt with means to test concepts regarding the facets of a "Media Class", the title of this column reflects the perspective of "Mentoring Media", and secondary course titles are emerging as "Media Classes" in many California high schools. The underlying purpose of this training is often not exactly lost, but is at least hidden, within the endless tumble of training and terms and equipment. Live production is nothing if it is not busy.

Prior to one of the school-year breaks, therefore, during one of the partial weeks with their "winding down" atmosphere, broach a discussion on the philosophical aspect of Communication. Tease out the importance of separating Communication as the fundamental underlying purpose of the tools of Media, and tie in the Fair Use Guidelines of U.S. copyright law which ought to have been covered at the outset of the course. This leads to some really excellent discussion of balance and fair play within the entire communications field. Learners have a keen sense of fair play in their daily lives, they are well aware of their vulnerability with regard to grades and their reliance on the ethics of their instructors for equable treatment.

There are those who would argue that the questions of ethics and fairplay are out of place in the classroom, and suggest that sophist discussion of balance, fair play, and a sense of ethics with regard to transmitting information should be left to other disciplines. I submit transmitting information is just a really a tough job. It requires sharp honing of behaviour and actually a lot of self-discipline. Few are those in the communications field who do not have opinions of their own, and great is the temptation to use their power to convince their audience rather than convey information, i.e. present all sides of an issue and settle back to see the results. This ability to separate business from personal may well be one of the greatest challenges to those in this field.

Separating and explicating the clear duty of communications personnel to transmit information, not opinion, making this an explicit rather than implicit mandate, goes beyond important. It absolutely serves to affirm and emphasize the incredible, nearly unlimited, power of the field that media learners are entering. With that power goes tremendous responsibility. The open question developing this practice in a separate training program, may be a topic for serious consideration as courses are developed in the future. 